Marquette University

e-Publications@Marquette

$1-1-2004$

\title{
The Agency-structure Model and the Embedded Individual in Heterodox Economics
}

John B. Davis

Marquette University, john.davis@marquette.edu

Published version. "The Agency-structure Model and the Embedded Individual in Heterodox Economics," in Transforming Economics: Perspectives on the Critical Realist Project. Eds. Paul Lewis. London: Taylor \& Francis (Routledge), 2004: 132-151. Publisher Link. (C) 2004 Taylor \& Francis (Routledge). Used with permission. 


\title{
7 The agency-structure model and the embedded individual in heterodox economics
}

\author{
John B. Davis
}

\section{Introduction}

Two main differences distinguish mainstream and heterodox economics' ways of understanding the individual. First, whereas mainstream economics treats individuals as atomistic beings, heterodox economics generally characterizes individuals as being embedded in networks of social and economic relationships. Second, whereas there is a fair amount of agreement across mainstream economists over what the atomistic conception of the individual generally involves, different schools of heterodox economists tend to disagree over how to understand the nature of the individual and individual embeddedness. Indeed, heterodox economists within different schools also often disagree over how individual embeddedness is to be understood. This suggests the need for developing a concrete strategy for investigating the topic of the embedded individual in heterodox economics. My strategy in this chapter is first to distinguish two broad approaches within heterodox economics to understanding the individual as a socially and economically embedded being, and then to attempt to show how a critical realist understanding of individual and society helps us understand these two approaches. Preliminary to doing this, however, I set out a general understanding of what it means to talk about individual embeddedness, within which these two broad approaches can be distinguished and explained. This threepart discussion - general understanding, two broad approaches, and particular heterodox schools - describes the overall order and structure of the chapter.

The next two sections of the chapter set forth a general understanding of what it means to talk about individuals as bcing embedded in networks of social and economic relationships. Section II begins by surveying a collection of concepts used in describing embedded individuals that have been developed in the social psychology literature on the subject of the individual's 'self-concept.' Section III then advances a general conception of the embedded individual based on a critical realist understanding of the relationship between individual and society. Here I draw on Lawson's 
Economics and Reality Part III agency-structure analysis to describe a complex dynamic between individuals and social-economic structures which transforms each as well as the relationship between them over time. Lawson's analysis is general in that the form or character of the means by which individuals and structures each operate upon one another is left intentionally uninterpreted in the interest of characterizing the relationship between them in the broadest possible terms. 'Structures' for Lawson include not just more highly institutionalized social arrangements and social positions, but also uncodified, more informal social norms, routines, and conventions. Indeed, it is differences over the relative importance of these respective types of means by which individuals and structures influence one another - and therefore differences over interpretation of the concept of 'social structure' - that provide us with a basic distinction between the two broad heterodox approaches to understanding individual embeddedness.

Section IV distinguishes two broadly different approaches to understanding the embeddedness of individuals in networks of social and economic relations in terms of two different types of means by which individuals and society influence one another: institutions and social values. The institutions approach works by examining how institutions structure interactions between individuals, and how individuals in turn influence the structure of society by creating and transforming institutions. The social values approach works by examining how social values structure interactions between individuals, and how individuals in turn influence social values. Though I dichotomize two approaches to understanding the agency-structure relationship, there are clearly important similarities between the two approaches. This reflects the fact that they both draw on a single understanding of individuals as socially and economically embedded rather than atomistic.

Section $\mathrm{V}$ then briefly summarizes thinking about agency and structure in reference to six heterodox economic schools - institutionalist economics, social economics, radical/Marxist economics, Post Keynesian economics, feminist economics, and ecological economics - according to their respective reliance upon one or both of the two approaches set out here. The section concludes with summary remarks regarding what critical realism offers to the overall framework.

\section{Social psychology's concept of the individual: the 'self-concept'}

The concept of the individual, or more specifically the 'self-concept' as it is generally termed in the social psychology literature (Rosenberg 1979; Gecas 1982; Demo 1992), dates from the late 1960s, and reflects the nature of social psychology as an interstitial social science shared by sociologists and psychologists. The concept has been said to be 'rapidly becoming the 
dominant concern within social psychology ... as part of the general intellectual shift from behavioral to cognitive and phenomenological orientations' in both sociology and psychology (Gecas 1996). Those with a more sociological orientation within social psychology usually examine the social antecedents of individual behavior, whereas those with a more psychological orientation within social psychology rather tend to investigate the social consequences of individual motivation and behavior. Social psychological research on the concept of the self as a whole combines these two orientations by investigating how individual identity is reflexively constituted and reconstituted out of a socially influenced process of self-evaluation, self-imagining, and self-awareness engaged in by the individual. The self-concept is thus a concept of individual identity understood as 'situationally variable,' yet also relatively stable, as suggested by the idea of a 'moving baseline' subject to fluctuation and change (Demo 1985). The concept reflects social psychology's comparatively more dialectical mode of investigation in comparison with the more uni-directionally oriented dynamics of sociology and psychology, which examine either the impact of social structure on the individual or the impact of the individual on social structure. Here I provide only a very brief review of a number of themes in the social psychology literature that bear on the individual self-concept. In my view, the social psychology literature on the self-concept is valuable for thinking about individuals as socially and economically embedded, because of its emphasis on the individual as a being continually constituted and reconstituted in a socially influenced process of selfevaluation.

The self-concept itself in the most general sense, then, is that understanding which individuals acquire of themselves as a result of the influence of social structures upon their processes of self-appraisal (Rosenberg 1979). Within this general understanding, the self-concept is conceived both (i) in terms of self-appraisal processes in which the individual thinks of herself as a subject, an 'I,' and a knower, and (ii) in terms of self-appraisal processes in which the individual sees herself as an object for others, a 'me,' and a self known by others. Social psychologists with the former, more psychological orientation explain the self-concept in terms of individual desire to establish a sense of self, using the term 'self-esteem' to emphasize 'the evaluative and emotional dimensions of the self-concept.' Social psychologists with the latter, more sociological orientation use the concept of individual identity to 'focus on the meanings comprising the self as an object' within a social context (cf. Gecas 1982: 4). The former emphasis on self-esteem makes the individual activity or agency that produces a self-concept central, whereas the latter emphasis on identity gives greater weight to society's influence on individual self-evaluation. 
Both orientations, however, assume that how others judge an individual influences the formation of the individual's self-concept (whether in the self-esteem sense or in the identity sense), and use this to argue that the self-concept involves a sort of 'reflected' self-appraisal. At the same time, it is also recognized that the self-concept as a kind of reflected self-appraisal still lacks good empirical foundations, since while it is plausible to say that people's self-concepts reflect the way they believe others see them, there nonetheless seems to be little evidence supporting close correspondence between people's self-concepts and the way people are actually seen by others. The problem is that it is not obvious just how people's 'self-evaluations are influenced by the feedback received by others' (Shrauger and Schoeneman 1979). Possible reasons for this have been suggested for both the self-esteem and identity understandings of the concept. The way in which individuals establish self-esteem may be selective with respect to good and bad opinions of others as well as with respect to whose opinions are observed. Alternatively, the way in which individuals establish an identity concept may reflect norms of social interaction in a culture, whereby customary practices condition the form of appraisal from others, and create differences between how others perceive an individual and express their views of that individual (Goffman 1959). Thus in addition to the basic psychological and sociological types of approaches to the self-concept itself, there are also distinct psychology-based and sociology-based strategies for explaining, the ways in which others' opinions feed back upon and affect individuals' self-appraisal. ${ }^{1}$

But for our purposes, the most important aspect of the social psychology literature on the self-concept is its shift toward greater emphasis on the dynamic effects of interaction between the individual and society. Thus while the earlier social psychological literature on the self-concept tended to emphasize constancy and stability in individuals' self-concepts, in order to develop a coherent conception of a 'maintained' self, there now appears to be increasing agreement that emphasis should also be placed upon a 'plasticity of characteristics previously assumed to be stable throughout the life course', implying a more "'open" or "unfinished" character of the human organism in relation to its environment' (Dannefer 1984: 107; cf. Demos 1992). One such view, widely influential in the social sciences and health fields, is of the selfconcept as an organized succession of different types of ages, for example developmental age as a set of meanings associated with personal passage from youth through old age, social age as the social meanings of age at various transitions and turning points in social life, and historical age as meanings associated with the experience of different cohorts and generations in history (Elder 1991). But there are many other ways in which the plasticity of the individual could be understood when taking the idea of the individual as a sort of 'moving baseline.' Thus in principle 
the social psychological self-concept should be amenable to employment in economics frameworks that emphasize dynamic, mutually constituting relationships between individual and society.

What, then, does the social psychology thinking on the self-concept have to offer heterodox economics on the subject of the relationship between individual and society? In the first place, it offers new resources in the idea of the individual as specifically a reflexive being, or as a being that forms a self-concept in a social context. Heterodox economists generally stress the influence of society on the individual per se, but less often investigate how this influence produces changes in individuals' selfconcepts. Indeed the issue of individual or agent identity itself infrequently arises in heterodox economics. Second, the social psychology of the individual is valuable in that it emphasizes the idea of the individual as an active being. Individuals are actively engaged in reconstituting their self-concepts in light of social influences upon them. Generally methodologically holist, heterodox economics emphasizes the active influence of society on individuals, but less often explains how individuals in turn actively influence social structures. Third, social psychology's self-concept offers opportunities to heterodox economics in that its combination of the different causal strategies of sociology and psychology makes reciprocal cause and effect relationships central to explaining both individual and society as both cause and consequence of one another. Heterodox economics, by understanding individuals as socially and economically embedded, already employs these themes, but would be better able to develop them were it to incorporate a more developed concept of the agent as an active being. ${ }^{2}$

In this latter regard, the agency-structure model of individual and society, as developed in Lawson's Economics and Reality, provides a way of incorporating the key ideas involved in social psychology's self-concept in heterodox economics' general understanding of individuals as socially and economically embedded, since Lawson's analysis of the agency-structure model is both rooted in a heterodox economics vision, and employs a thinking about individuals and agency quite close to social psychology's self-concept. I thus now turn to Lawson's analysis to further develop a heterodox account of the relationship between individual and society that explains human agency as reflexive and active and the relationship between individual and society as one of reciprocal cause and effect.

\section{The agency-structure model of individual and society}

The inspiration behind the agency-structure model lies in the idea that the opposition between methodological individualism and methodological collectivism can be overcome by regarding agency and structure as dynamically interactive. An early formulation is Giddens' 
influential 'structuration theory,' which treats individuals and social structures as interdependent, or as a duality, such that each may be said to help constitute the other, especially through recurrent social practices (1976, 1984). Bhaskar (1979 [1989]) and Archer (1995) revised and extended Giddens' thinking, principally by seeing reality as stratified and multi-layered with emergent properties differentiating one layer or level from another (cf. Hodgson 2000: 5-13; also Collier 1994). Lawson developed this latter, critical realist conception of the agency-structure relationship specifically for economics in Part III of his Economics and Reality (1997), and used it primarily to critique the methodological posture of mainstream economics. I use it instead to understand the embedded individual in heterodox economics, and carry out an ontological analysis of agents in economic life. Central to this latter project is how the model accounts for the reciprocal effects of human agency and social structure upon one another, and how the model treats human agency as intentional activity. I argue that this framework is in need of a fuller understanding of the individual, and attempt to provide one along the lines developed in social psychology. In my view, then, an agency-structure model expanded to include an account of individuals can account for processes of social reproduction and transformation that both bear upon and help us understand the identity of individual economic agents. This fuller account with its alternative conception of the individual economic agent as socially and economically embedded is what I believe is most needed for heterodox economics to distinguish itself from orthodox economics.

The basic idea of the agency-structure model, then, is that social structure depends on human agency, and human agency depends on social structure. First, consider how social structure depends upon human agency. The agency-structure model of individual and society is specifically a critical realist analysis in that, as a realist model for a social science, the model makes 'social structure dependent upon human agency ... open to transformation through changing human practices which in turn can be affected by criticising the conceptions and understandings on which people act' (Lawson 1997: 158, original emphasis). That is, social structure changes, because human practices change, because people critically evaluate the ideas which those practices reflect. This does not imply, of course, that human agency is an unmediated force acting on social structure free of all social influence. The process of replacing one set of 'conceptions and understandings' with another clearly involves the idea that individuals operate upon an inherited set of materials. So indirectly social structure still plays a role in criticism. But this raises a long-debated question. Might this not imply that human agency is ultimately only a product of social structure, and that it is a mistake to say that social structure depends on agency? 


\section{John B. Davis}

One way to resist this conclusion is to say that when we take individuals as agents of change, their self-conceptions and selfunderstandings, which individuals continually organize and reorganize to create their self-concepts, play a central role in organizing the great mass of 'conceptions and understandings' individuals regularly have about the world. The process of forming a self-concept, involving the replacement and abandonment of one set of self-conceptions with another, is understood in social psychology as a reflexive and active process in which individuals absorb a range of conceptual materials from society (say, a grasp of customs, understandings of markets, knowledge of legal principles, etc.), and then actively integrate these materials in terms of their self-conceptions (say, that I ought to behave in some way or another, that I can participate in such-and-such a market in some fashion, that the law applies to me in a particular manner). That they may be said to do this implies that they are able to distinguish themselves as selves (as I's or me's) about which they organize these materials. As a property of individuals as agents, that is, reflexivity implies that individuals possess a measure of detachment or relative autonomy from the social influences operating upon them though they draw upon them. The critical realist understanding of the agency-structure relationship implicitly invests individuals with this active capacity when it describes them as regularly engaged in 'criticising the conceptions and understanding on which people act.' What social psychology adds to this is the idea that this criticism also extends to self-conceptions and self-understandings, and the capacity to engage in this further criticism enables us to see individuals as relatively autonomous agents. From this perspective, it is fair to say that in the agency-structure model, social structure influences individuals, yet is also itself dependent upon human agency.

Now consider the other side of the agency-structure model, or the reciprocal dependence of human agency on social structure. Given what has been said above, how exactly are we to understand this dependence and the way that society influences individual agency? Lawson makes two points in this regard. First, in rejecting the reductionist project of methodological individualism, he argues that 'social structures (rules, relations, positions)' are real in the sense of being irreducible to the actions of individuals (1997: 161). Second, social structure is said to be a precondition for individual action in that, as said above, individuals draw upon it when acting. More specifically, in rejecting the orthodox understanding of rationality, Lawson substitutes a theory of situated rationality whereby: 'At any given point in time any individual is situated in a range of positions' associated with which are 'rules to draw upon, obligations to fulfill, structures of power to utilise and be influenced by' (1997: 187). These positions, and the rules, obligations, and structures of power upon which they depend, constitute the social preconditions for 
individual action which help explain how human agency depends upon social structure.

What we may add to this in drawing on social psychology's selfconcept is further understanding of just how these social preconditions impose their influence on individuals. When we add a self-concept to our understanding of individuals, we say that society's rules, obligations, and structures of power help determine the form and shape of individuals' self-conceptions. For example, a particular social obligation, such as that an individual return a favor, involves a set of expectations of that individual which create a set of self-understandings for that individual. Society's rules, obligations, and structures of power, that is, really only become preconditions for individual action when they are translated into conceptions that apply specifically to particular individuals in terms of the self-conceptions they generate. The theory of embedded rationality broadly emphasizes the relationship between social structure and individual positions within a social structure. The social psychology selfconcept specifically links social structure and positions through the particular individual's apprehension of this relationship, as formulated in terms of that individual's self-conceptions and ultimately self-concept. Social structure, then, is a precondition for human agency in the sense of situating rationality in social positions, but, because individuals engaged in forming self-concepts actively grasp their social positions in applying rules, obligations, and expectations to themselves, human agency is dependent upon but not determined by social structure.

Thus human agency depends upon social structure, just as social structure depends upon agency. The agency-structure model of individual and society consequently aims to explain the reproduction and transformation of both human agency and social structures. A consequence of this is that it may be said to avoid the (twin but opposite) errors of voluntarism and reification/determinism, where voluntarism explains social structures as essentially the creation of individuals (as in some methodological individualist accounts), and reification/ determinism sees individuals as essentially the product of social structures (as in some methodological collectivist accounts). The way in which the model achieves this is by emphasizing that human agency is intentional activity. From this two things follow. First, 'most structural reproduction and/or transformation arises as the unintended product [of human intentional activity], whether or not desired or even recognised' (Lawson 1997: 169). Though human agency creates social structures, intentional activity cannot fully explain the evolution of social structures (the error of voluntarism), because its results are in significant degree unintended. We might add to this that if individuals operate in some fundamental sense in terms of their self-concepts, then the scope of their activities is necessarily restricted, and the consequences of their actions are likely often unintended. Second, 'If the reproduction/transformation 
of social structure is rarely an intended project, it is equally the case that the individual agents are not always aware, certainly not discursively or self-consciously so, of the structures (such as language rules) upon which they are drawing' (1997: 169). We may add here that if individuals' selfconcepts are by nature always open and unfinished, they cannot be expected to smoothly accommodate all social influences and feedback from others, so that the individual's awareness of the import of social structures is always incomplete. This reinforces the idea that though social structures influence human agency, they do not determine intentional human activity (the error of reification/determinism).

Yet if this account depends upon treating human agency as intentional activity, what are we to say about the pervasiveness of highly routinized forms of activity in human society? Lawson allows that much of human behavior does not take on the aspect of being intentional. If we distinguish between discursive and tacit consciousness, where the former involves conscious reflection on a particular subject, and the latter involves individuals monitoring their conduct at a subconscious level, then it seems obvious that individuals often rely upon a body of tacit knowledge and skills in order to do such things as follow rules, observe norms, and act in accordance with conventions without reflecting directly upon doing so. But such activity is still purposeful, and thus also fairly treated as a form of intentional activity. Were the individual interrupted in the performance of an episode of rule-following, typically a reason for following the rule could be given. This verdict is important not just because routine is such an important part of human behavior, but because understanding routinized behavior as a form of intentional activity is important for developing a more complete understanding of the individual and human subjectivity in the agency-structure model.

Generally, Lawson's discussion of the processes of reproduction and transformation in the agency-structure model tends to associate these processes with the evolution of social structures. But to be complete, the processes of reproduction and transformation of agency and social structure should also be associated with the evolution of human subjectivity, the agency side of the model. Here his discussion of routines as a form of intentional activity opens the door to one way to go about this. Lawson asks why so much human activity is routinized. Part of the answer lies in the simple fact that we seem unable to apply discursive decision-making to all occasions in life where it might be possible to do so. But if this is necessary to explaining routines, it is not sufficient, since other responses to this inability, such as inactivity, are also available. A sufficient explanation that Lawson contemplates is that this human inability causes individuals anxiety and stress, and that individuals accordingly rely on routinzed bchavior to reduce this anxiety and stress. Then the fuller account of the agency-structure model that includes an explanation of the evolution of human subjectivity would involve 
describing how routines evolve together with individuals' evolving strategies for combating anxiety and stress.

Yet it is not far from saying this to the social psychology idea of the individual self-concept. Indeed Lawson adds that individuals may be thought to have a need for 'inner security' which in turn may reflect a need for 'a significant degree of continuity, stability and sameness in daily affairs' (1997: 180). A way of understanding continuity and stability in life is in terms of how they promote continuity and stability in an individual's self-concept. Recalling the 'moving baseline' expression, individuals might be said to rely on routinized activity, because doing so promotes continuity and stability in their self-concepts. Lawson in fact suggests just such an argument when (following R.D. Laing and Giddens) he treats a need for inner security as a need for an 'ontological security,' where the 'psychological origins of ontological security are to be found in basic anxiety-controlling mechanisms ... hierarchically ordered as components of personality' (Giddens 1984: 50; quoted in Lawson 1997: 183). Ontological security, that is, applies to a subject, or the individual. Thus, the processes of reproduction and transformation that are explicitly associated with the evolution of social structures in Lawson's agency-structure model seem equally applicable to the evolution of human subjectivity. Here I don't recommend this or any other particular account of how to go about understanding the evolution of human subjectivity. It is enough for the purposes of this chapter to emphasize that a general agency-structure model is a model of interactive processes of reproduction and transformation affecting both social structures and human subjectivity.

There is one minor point about Lawson's discussion to be made before passing on to the two main approaches or ways of understanding individual embeddedness in heterodox economics. The agency-structure model, by using the term 'structure', seems to favor one of the two general approaches identified at the beginning of this chapter regarding the means by which individuals and society influence one another, namely, that approach which emphasizes the role of socio-economic institutions rather than that which emphasizes social values. However, it is clearly not Lawson's intent to favor one of the two general approaches, since his discussions of 'structure' include a variety of social apparatuses which are better represented in terms of social values, or perhaps value structures, than in terms of institutionalized social arrangements. More careful discussion of this distinction must be postponed to the next section. But it seems fair to say at this point that Lawson's discussions of rules and conventions allow a role for social values, and need not only be understood in terms of more institutionalized social arrangements. 'Structure' of course also refers to institutionalized social arrangements. The agency-structure model, then, is general in that it allows a role for 
both types of mechanisms of influence upon individuals, while 'structure' is to be understood both in terms of institutions and in terms of values.

\section{Heterodox economics' two approaches to the agency-structure relation}

In this section I contrast two broadly different types of ways of understanding the reproduction and transformation of both social structures and human subjectivity according to two different kinds of means by which individuals and society each influence one another. At the beginning of this chapter, I characterized the difference between these two approaches as a difference between how more highly institutionalized social arrangements and social positions influence and are influenced by individuals, and how less formal social norms, routines, and conventions influence and are influenced by individuals. I thus begin here by explaining (i) how individuals influence the transformation and evolution of institutions and social values (Lawson's topic of how social structure depends upon agency). Then I turn to the reciprocal matter of (ii) how social-economic institutions and social values differ in the ways in which they operate upon individuals (Lawson's topic of how agency depends upon social structure). Finally, I outline (iii) the overall agency-structure cause-and-effect system, in order to provide an account of its dynamics in terms of tensions between both kinds of factors operating on both individuals and social-economic structure in the form of institutions and social values.

\section{(i) Individuals' different kinds of influence on institutions and social values respectively (social structure's dependence on agency)}

Individuals may be said to influence institutions when they engage in interaction which departs from what institutions permit or require, and which subsequently brings about changes in existing institutions or leads to new ones. It seems fair to say that much individual action and interaction between individuals is not structured by institutions. Take, for example, antitrust laws as social-economic institutions determining the scope of individual action for individual business firms. In the past such laws have generally been national in scope, leaving the efforts on the part of firms to restrict competition among themselves across national boundaries largely unregulated. In response, in many countries existing antitrust laws have been reinterpreted to accommodate extra-territorial economic behavior, while new supranational antitrust agreements between countries have also begun to emerge. Thus institutions have been influenced by interaction between individuals (or firms taken as individuals) occurring outside of the framework of existing institutions. 
Understanding these firms in self-concept terms, we might say that this overall development begins when firms determine how exceptions in existing laws apply to themselves. That is, they entertain new selfconceptions by, in Lawson's language, 'criticizing' the practices and institutions under which they operate. This then creates the opportunity for their interaction with one another in restraint of competition, which in turn may lead to change in institutions. Thus individual action and interaction outside of institutional frameworks tend to lead to change in those frameworks.

Alternatively, individuals may be said to influence social values when they share personal values different from widely held social values, and their doing so subsequently brings about a change in social values. Personal values may both coincide with and also differ from widely held social values. When they differ, the 'personal' character of an individual's values is reinforced by their apparent lack of widespread acceptance. But appearances may be deceiving, and it is possible that so-called 'personal' values are shared by many individuals, unbeknownst to them. Should individuals, then, discover that they in fact share what they believed was largely personal, their personal values may begin to acquire a social character as well. For example, consider an electoral process. Prospective voters may share views about candidates and outcomes before public discussion and debate define electoral issues. As the latter proceed, however, individuals may discover they share others' opinions and values. In self-concept terms, individuals find that their 'personal' values are shared when they formulate new self-conceptions regarding how their 'personal' values compare with those of others. Social values may thus emerge from this recognition of shared personal values, and consequently social values are influenced by personal values.

Note that both of these two means by which individual action and decision influence social structure - interactions between individuals affecting institutions and sharing personal values affecting social values are supra-individual in character in that they explain action and decision in terms of relationships between individuals. This implies that in a complete agency-structure model we ought to be able to explain the human subjectivity side of the model not just in terms of the behavior of collections of relatively independent individuals but in a stronger sense of individuals somehow acting together. That is, we need some coherent means of discussing how individuals use the language of 'we' as well as

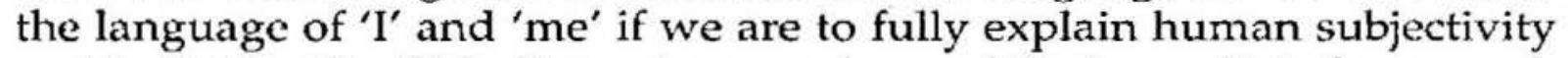
and individuality. This discussion goes beyond the immediate framework of this chapter, but I do treat it in an investigation of the concept of collective intentionality in connection to the theory of the embedded individual (Davis 2003). 


\section{(ii) Influences of institutions and social values on individuals (agency's dependence upon social structure)}

First, I suggest that when social-economic institutions influence individual action and decision-making, they do so chiefly by altering the scope of action and individual decision-making. An institution, say a national labor law or an environmental regulation, limits the space of activity in which individuals can act, and thus leads them to focus their decisionmaking on an allowable space of activity. Individuals' subjectivity and self-concepts are consequently developed and transformed primarily in terms of their extent of application, rather than in terms of changes in their meaning or content. Some might wish to argue that institutions also influence the content of action and decision-making. Rather than argue this point, here I attempt to follow others more knowledgeable than I about the nature and history of thinking about institutions, who emphasize that institutions are best defined as networks of social relations and positions generally accepted by those to whom they apply (cf. Rutherford 1994: 182n). Thus institutions appear to have their primary impact on individuals by determining the space of allowable activity. This is also consistent with their characterization as more highly settled, more formal social arrangements and associated sets of social positions.

Second, then, social values may be said to influence decision-making and individual subjectivity by altering their content and basis. That is, should individuals rely on some given set of reasons or rationales when acting in certain circumstances, being influenced by social values normally means that they adopt new reasons or rationales for how they will act in those same or similar circumstances in the future. Moreover, since these new reasons or rationales constitute a new basis for individual action, they should also be thought to involve changes in individuals' selfconceptions and self-concepts. For example, adopting new religious views typically changes an individual's actions and interactions with others. At the same time, a change in religious views generally means a change in the individual's self-concept as it applies to the individual's perceived relation to the supernatural. At issue here is less the scope of existing views than the character of those views itself. Thus it seems fair to say that the impact that social values have on individuals is primarily in terms of the meaning and content of their actions.

To be sure, because institutions and social values are similar in important respects, it is somewhat artificial to parcel out their effects as I have done here. Thus, as will emerge in what follows, a good part of the justification for the distinction above lies in what it permits us to say about complex processes of reproduction and transformation in an expanded agency-structure model. I now turn to an account of the model that combines the discussion of the last two sections. 


\section{(iii) The overall agency-structure model}

Institutions and social values influence the scope and content of individuals' action and decision-making respectively, while individuals' interactive activity and shared values influence institutions and social values respectively. These processes clearly occur simultaneously. Though institutions create a framework within which individuals act, as for example exists with any set of laws, individuals' interactions with one another may test that framework, perhaps causing laws to be rewritten. And though social values determine a basis for individual action, as when a conception of human rights guides individual decision-making, individuals may find that they share values regarding those rights at odds with that conception, perhaps leading to revision in a community's conception of human rights. At the same time, it seems reasonable to say that these two pairs of reciprocally occurring processes (institutions/ individual interaction and social values/shared personal values) also somehow influence one another, and that we ought in principle to be able to describe how this occurs. It pays, however, to be cautious about attempting to over-describe the agency-structure model as if the social world were to be captured as a complete system of interconnections, since the social world is arguably stratified, such that some levels of activity are emergent upon others, and thus strictly speaking not interconnected. ${ }^{3}$ Thus to avoid portraying the world as a system of interconnections, and yet still provide an account of the overall agency-structure model, in what follows I conceptualize the relationship between these two pairs of reciprocal processes in terms of possible tensions between them in an overall process that reproduces and transforms both agency and structure. Further, since change originates on the agency side of the agency-structure model, I explain these tensions as arising from the actions of individuals, first in terms of how they generate a change in social values, which are then in tension with society's institutions, and second in terms of how they generate change in society's institutions, which are then in tension with its social values.

Consider first how change in a society's institutions may be brought about by change in its social values, for example in terms of changes in the relationship between a society's legal framework and its conception of human rights. In the late eighteenth and early nineteenth century there was little tension between the basic legal framework of the United States, the Constitution, and reigning social values that guaranteed human rights to the European-derived population while denying them to the Africanderived population. Yet by the middle of the nineteenth century social values regarding human rights were in a process of change (especially in the North), and were increasingly perceived to be at odds with existing legal institutions. More specifically, the social values/shared personal values reciprocal process underwent change as the shared personal values of 
religiously inspired slavery Abolitionists gained weight in the determination of Northern social values. This change in social values helped generate change in US Iegal institutions by the middle of the nineteenth century, including amendments to the Constitution itself. It is true that this institutional change was also brought about by interaction between individuals outside of the framework of existing legal institutions, the war between the North and the South being an obvious example. But most historians agree that the new values in the North regarding the unacceptability of slavery played a key role in bringing about the war and subsequent institutional change, and thus a change in social values may be seen as bringing about the change in institutions. ${ }^{4}$

Both agency and social structure were reproduced and transformed in this process, but it is worth attending a bit more closely to change and transformation on the agency side of the model in light of the emphasis placed on understanding the embedded individual and subjectivity in this chapter. Thus, a change in shared personal values comes about when individuals inherit conceptual materials (the influence of structure on agency) and then, in 'criticizing' these materials and the practices they entail, come to entertain new self-conceptions. Northern Abolitionists, that is, grasped the moralities of a society accepting of human rights for some but not for others, found the self-conceptions these moralities implied unacceptable, and formed new self-conceptions regarding their personal stances toward slavery. As these new self-conceptions and the personal values they involved began to be shared by many individuals, social values regarding human rights and slavery began to change. Here, the question naturally arises as to what brought about the abandonment of old self-conceptions and the adoption of new ones in this process? But in an important sense this question is inappropriate. The agencystructure model presupposes that a genuine dynamic exists with influence on change arising in both agency and structure. The expanded agency-structure model with a more developed account of individuals and subjectivity explains the dependence of structure on agency by the treatment of individuals in social psychological terms as reflexive and active. In short, individuals simply have a genuine capacity to criticize their conceptions and self-conceptions.

Consider now how change in a society's social values can be brought about by change in its institutions. The feudal system in medieval Europe involved a set of economic institutions, such as manorial production and inherited class relationships, and a set of associated social values, such as that individuals have a customary, inherited place and vocation in life and that ruling classes had paternalistic responsibility for the well-being of the laboring classes. Market behavior, as was to emerge with capitalism, involves an alternative set of economic institutions, such as contracts and the wage system, and its own set of social values, such as the rights of private property and the idea of the individual as a locus of freedoms. 
When in the seventeenth and eighteenth centuries individuals began to place greater reliance on market relationships with one another, they also began to put in place new economic institutions not consistent with the social values of feudalism. In this case, changes in individual interaction brought about change in economic institutions, which in turn generated tensions between institutions and social values. Of course it might alternatively be argued that change in shared personal values was also a source of change in the social values of the time. I don't argue that this was not the case. But it seems many historians would agree that a change in economic practices played a particularly important role in Europe's abandonment of feudalist social values, and thus a change in institutions may be seen as bringing about a change in social values.

Again, in light of the emphasis placed in this chapter on the theory of the embedded individual and the agency side of the agency-structure model, it is worth attending a bit more closely to how changes in individual interaction might reflect individuals' changing selfconceptions. Thus, when individuals restricted themselves to customary, feudal economic relationships, their self-conceptions were traditional, inherited ones. But when they began to engage in market transactions, they had to see themselves in new, unfamiliar capacities. Taking individual interaction outside of established institutions to be primarily a matter of changes in the scope of activity, this change in individual selfconceptions and self-concepts was a matter of not just a change in the scope of individual activity, but also a change in scope of individuals' selfconceptions, which were enlarged to include the capacity to produce for exchange. The emergence of market institutions solidified this change. Again, I do not attempt to explain why individuals were able to seek out new forms of economic interaction after centuries of traditional economic relationships. The agency-structure model makes agency dependent upon structure, but also structure dependent upon agency, and the appearance of new forms of individual interactions in markets counts as evidence of the latter. The emphasis here lies rather on developing a clearer conception of changes in agency, or individuals' subjectivity. Thus whereas changes in shared personal values alter the basis on which individuals form self-conceptions, changes in individual interaction enlarge the scope of those self-conceptions.

Of course, my two examples - the nineteenth-century rise in opposition to African-American slavery in the United States and the emergence of market behavior in medieval Europe - are only highly schematic characterizations of complex historical processes that have been treated at much greater length by historians. My purpose in setting them forth is to illustrate two things: first, that the agency-structure model can advantageously be broken down into two types of reciprocal processes (institutions/individual interaction and social values/shared personal values), and, second, that enlarging the model to incorporate a 
more developed understanding of embedded individuals and subjectivity adds to the explanatory power of the model. Since this chapter seeks to use the agency--structure model to help develop a conception of the embedded individual for heterodox economics, I do not attempt here to further elaborate or defend this interpretation of the model, but rather now turn to a classification of heterodox economics schools both according to their apparent reliance or emphasis on institutions and/or social values as means by which individuals and society influence one another, and according to their associated conceptions of the embedded individual.

\section{Six heterodox schools: concluding remarks}

The six schools of heterodox economics I address, roughly according to their order of emergence in contesting post-war orthodox economics, are: institutionalist economics, social economics, radical/Marxist economics, Post Keynesian economics, feminist economics, and ecological economics. None are explicitly understood by their proponents in terms of the agency-structure model, but all arguably rely on the principal tenet of the model, namely, that agency and structure, however identified, are dependent upon one another. Thus all generally avoid the (twin but opposite) errors that face social science and social theory, voluntarism and reification/determinism, and accordingly all are neither methodological individualist nor methodological collectivist in orientation. First, then, how may these schools be classified according to their emphasis on institutions and/or social values as the means by which agency and structure influence one another?

Institutionalist economics and social economics are relatively easy to characterize in that traditionally the former has emphasized institutions and the latter social values as the chief means by which agency and structure influence one another. Institutionalism does not ignore social values, but largely treats them as reflecting institutional relationships. Social economics does not ignore society's institutional structures, but generally explains them as reflective of social value attachments. In contrast, radical/Marxist and Post Keynesian cconomics seem to involve conflicting views regarding the roles of institutions and social values. Radical/Marxist economics emphasizes the institutionalized nature of class relationships underlying labor exploitation and capital accumulation, but also emphasizes the role of class consciousness in revolutionary and liberation struggles, which involves social values. Post Keynesian economics emphasizes the institutionalized nature of liquidity and uncertainty in a capitalist market economy, but on the social value side also emphasizes investor animal spirits and the question of public commitment to demand management. Finally, feminist and ecological economics seem to have evolved in the weight they assign to institutions 
and social values, though in different directions, with feminist economics now placing greater weight on social values and ecological economics now placing greater weight on institutions. Feminist economics originally gave greater weight to laws and institutionalized systems of discrimination in the economy in explaining gender inequality, but has increasingly emphasized gendered social attitudes, as are for example manifested in household relationships and child-rearing, as important. Ecological economics originally emphasized public consciousness regarding the environment, but has given increasing weight to changing legal frameworks limiting corporate activities.

What, then, may we conclude from this regarding different conceptions of the embedded individual in these heterodox schools? In institutionalism, individual embeddedness is understood chiefly in terms of the institutions/individual interaction reciprocal processes relating agency and social structure. That is, individual activity is influenced by institutions (agency depends on structure), and individual activity changes institutions (structure depends on agency). In social economics, individual embeddedness is understood chiefly in terms of the social values/shared personal values reciprocal processes relating agency and social structure. That is, social values and shared person values influence and depend upon one another. In radical/Marxist and Post Keynesian economics, individual embeddedness can be explained on both bases. On the one hand, this produces richness in explanation across these two schools when each is taken as a whole. On the other hand, since the two schools tend to be divided between those giving greater emphasis to either the institutions/individual interaction or the social values/shared personal values processes, general conclusions within the two schools about individual embeddedness are difficult to achieve. In feminist economics, individual embeddedness is increasingly explained in terms of the social values/shared personal values processes, though with the institutions/individual interaction processes as a framework within which this occurs. Similarly, in ecological economics, the institutions/individual interaction processes are explained within the social values/shared personal values processes. These two latter schools perhaps offer the most explanatorily powerful accounts of individual embeddedness in their implicit integration of both sets of processes in overall agency-structure analyses.

What these differing emphases suggest is that a general account of the individual as socially and economically embedded for heterodox economics could be based on a critical realist agency-structure model enlarged with social psychology thinking about the self-concept. Different heterodox schools give different kinds of emphasis to institutions and social values, but the agency-structure model can make use of both types of means in terms of two reciprocally occurring processes, institutions/individual interaction and social values/shared personal 
values, which each have effects upon one another. This overall framework, I suggest, is reflective of heterodox economics as a research programme alternative to mainstream economics. From this perspective, the different schools within heterodox economics might be classified according to their implicit implementation of this framework. At the same time, in so doing a general account of the individual as socially embedded begins to emerge for heterodox economics.

The explicit reflection about the agency-structure relationship prompted by an encounter with critical realism might also help heterodox economists to avoid a tendency which some of them display towards the provision of one-sided accounts of the means by which agency and structure influence one another. The risk that heterodox schools such as institutionalism and social economics run is that by concentrating so heavily on institutions and values respectively, they pre-judge the importance of those factors and thereby run the risk of offering a distorted analysis of the processes through which agency and structure interact with one another. Critical realism provides a timely reminder that the question of whether the interplay between structure and agency centers primarily on institutions or on social values cannot be answered $a$ priori but only ex posteriori through concrete research. Critical realism, then, leaves conceptual room for a variety of processes through which agency and structure interact and as a result is more able to do justice to the complexity of the structure-agency relationship than schools which prejudge its nature. And by alerting heterodox economists of these schools to potentially explanatorily significant avenues of influence that might otherwise be ignored, critical realism helps to further the development of explanatorily powerful economic analysis.

\section{Notes}

1 These different strategies also arise in connection with other standard (and related) topics of investigation in the social psychological literature such as 'role playing' and 'social comparisons,' which similarly concern how others' opinions influence individuals' self-appraisal.

2 See Lewis (2000) for a discussion of causal strategies in connection with the debate between Bhaskar and Harré.

3 Archer (1995) advanced this criticism of Giddens' structuration theory. Emergence may be defined as 'a relationship between two features or aspects such that one arises out of the other and yet, while perhaps being capable of reacting back on it, remains causally and taxonomically irreducible to it' (Lawson 1997: 63).

4 Another example along these lines is the struggle over the political rights of women. A social value transformation regarding whether women were entitled to basic political rights was caused by the increasing influence of shared personal values of those in the Suffragette movement in the early twentieth century. This led to institutional legal change beginning with voting rights to women, and continuing with more recent legislation such as the 1962 Equal Pay Act. 


\section{References}

Archer, M. (1995) Realist Social Theory: The Morphogenetic Approach, Cambridge: Cambridge University Press.

Bhaskar, R. (1979 [1989]) The Possibility of Naturalism: A Philosophic Critique of the Contemporary Human Sciences, Second edition, Brighton: Harvester.

Collier, A. (1994) Critical Realism: An Introduction to Roy Bhaskar's Philosophy, London: Verso.

Dannefer, D. (1984) 'Adult Development and Social Theory: A Paradigmatic Reappraisal', American Sociological Reviezv, 49: 100-16.

Davis, J. (2003) The Theory of the Individual in Economics, London and New York: Routledge.

Demos, D. (1985) 'The Measurement of Self-Esteem: Refining our Methods', Journal of Personal Psychology, 48: 1490-1502.

- (1992) 'The Self-Concept over Time: Research Issues and Directions', American Review of Sociology, 18: 303-26.

Elder, G. (1991) 'The Life Course', in E. Borgotta and M. Borgotta (eds) The Encyclopedia of Sociology, New York: Macmillan.

Gecas, V. (1982) 'The Self-Concept', American Review of Sociology, 8: 1-33.

- (1996) 'Self-Concept', in A. Kuper and J. Kuper (eds) The Social Science Encyclopedia, Second edition, London: Routledge.

Giddens, A. (1976) Central Problems in Social Theory, Berkeley: University of California Press.

- (1984) The Constitution of Society, Cambridge: Polity Press.

Goffman, I. (1959) The Presentation of Self in Everyday Life, New York: Doubleday. (1967) Interaction Ritual, New York: Doubleday.

Hodgson, G. (2000) 'Structures and Institutions: Reflections on Institutionalism, Structuration Theory and Critical Realism', unpublished manuscript.

Lawson, T. (1997) Economics and Reality, London: Routledge.

Lewis, P. (2000) 'Realism, Causality and the Problem of Social Structure', Journal for the Theory of Social Behaviour, 30: 249-68.

Mead, G. (1934) Mind, Self, and Society, Chicago: University of Chicago Press.

Rosenberg, M. (1979) Conceiving the Self, New York: Basic.

Rutherford, M. (1994) Institutions in Economics: The Old and New Institutionalism, Cambridge: Cambridge University Press.

Shrauger, J. and T. Schoeneman (1979) 'Symbolic Interactionist View of the SelfConcept: Through the Looking Glass Darkly', Psychological Bulletin, 86: 549-73.

Stryker, S. (1968) 'Identity Salience and Role Performance', Journal of Marriage and Family, 30: 558-64. 